\title{
Commentary on Magic-Size Nano Crystals (MSNCs)
}

\author{
Khanna Pawan $\mathrm{K}^{*}$ \\ Department of Nano-chemistry and Quantum Dots Development Laboratory, Defence Institute of Advanced Technology (DIAT), India
}

Submission: August 01, 2017; Published: August 09, 2017

*Corresponding author: Khanna PK, Department of Nano-chemistry and Quantum Dots Development Laboratory, Defence Institute of Advanced Technology (DIAT), Girinagar, Pune, India, Email: pawankhanna2002@yahoo.co.in

\section{Commentary}

Nanotechnology has greatly matured when it comes to the synthesis and preparation of nano-particles, colloidal solutions, dispersible and in dispersible nano-particles, hydrophilic and hydrophobic particles that include spherical particles, nano-rods, nano-tubes and in fact all sorts of nano-structured materials. Early development was focused on synthesis and characterization of metal nano-particles via bottom up approach which ranged from individual metal particles to bimetallic particles extending it to their alloys. Similarly, metal oxide nano-particles were generated through very mature and famous sol-gel methods and often nano-particles of most metal oxides are obtain via some modification of typical sol-gel method. Semiconductor nanoparticles have been the target of many researchers for photonic application for the past at least three decades and the one of the major requirement has been to obtain size range of below $10 \mathrm{~nm}$ as this range show the optimum quantum confinement and size dependent properties in their absorption and emission spectrum. Amongst the semiconductor nano-particles quantum dots of semiconductors have been the study of much rigorous research as these offer potential application such a light emitting diodes, solar cells, biomedical imaging, telecommunication, sensors, display devices based on electroluminescence etc. Still further focus has been centered on II-VI, IV-VI and III-V quantum dots. CdSe and ZnSe have often stolen the show amongst the IIVI quantum dots and when one goes deeper into their synthesis and trapping of size dependence properties; one finds that there lies much more excitement and potential below particle size of $2 \mathrm{~nm}$ [1-3]. Ultra-small $(<2 \mathrm{~nm})$ nano-particles have been popularly designated as magic-size nanocrystals and different authors have named then differently but similarly e.g. "magicsize" or magic-number nanocrystals or simply the nano-clusters (MSNCs). These crystals are also sometimes referred to as earlystage nano-crystal which they get thermodynamically stabilized.

The size range of less than $2 \mathrm{~nm}$ for CdSe had not found much attention until 1996 when it was first reported followed by reports thereafter. In magic size nano-clusters the appearance and disappearance of absorption peaks at well-defined wavelengths, is a major identification of their existence during and after their synthesis. These MSNCs after their formation and identification by absorption spectroscopy continue to grow if the either the reaction time is enhanced or the temperature but mostly their growth into larger crystal is temperature dependent. The absorption properties of MSNCs is quite different than their regular QDs e.g. a very basic difference is multiple absorption peaks much blue shifted in case of MSNCs and mostly single peak but could be along with an excitonic peak in case of QDs. These observation are normally true for II-VI semiconductor MSNCs however these could vary from material to materials e.g. CdSe obviously has different band gap than $\mathrm{ZnSe}$ and PbSe and therefore their MSNCs will have difference in their optical and emission properties and so on. Due to such small size as less than $2 \mathrm{~nm}$, these are expected to be potential fluorophore for biological imaging. Also, these MSNCs show broad emission spread across the entire visible range and due to this they emit off-white to white light under the impact of visible light of 354 $\mathrm{nm}$ wavelength. Such properties of MSNCs offer great potential for white light emitting devices. The scope of MSNCs for white light has been documented by number of researchers including the author himself. The author has his on-going research in the subject and has evolved a few articles published in international journal of repute. One of them was published by the Royal Society of Chemistry Journal Cryst Engg Commn in 2010 [4-6]. The semiconductor MSNCs of CdSe, ZnSe and PbSe have appeared in the literature with great application potential and there are others which already have been existing for over three decades e.g. fullerene and we all know the magic of this carbon compound or to call more appropriately a structure with 60 or 70 atoms has caused immense research scope with great application potential. C60 with varied geometry are brightest examples of magic carbon numbers. Magic number metal nano-clusters have also been known for a long time e.g. limited number of atoms hot sodium metal. Gold metal has been documented with 55 gold atoms, a sort of of "magic-number" clusters. Study of the MSNCs 
formation process is generally based on monomer activity and precursor injection and product growth temperatures. Thus the growth kinetics of magic-sized nanocrystals depends heavily on these parameters [7-9]. Normally semiconductor MSNCs have less than 100 atoms and structure stabilized with atoms as less as 20-32 have been reported for CdSe with absorption wavelength in the range of $250-400 \mathrm{~nm}$ because of monomeric to trimeric cluster of CdSe which eventually extend their unit number due to constant growth if the same is not terminated at desired experimental condition. Due to limited number of atoms in such nano-crystals, they undergo transformation in their crystal structure e.g. if hexagonal CdSe QDs normally have between 1001000 atoms and arrange in such a way so as to evolve a spherical morphology of the quantum dots in comparison to their MSNCs counterparts which show elongated appearance like rice grains when seen under transmission electron microscopy.

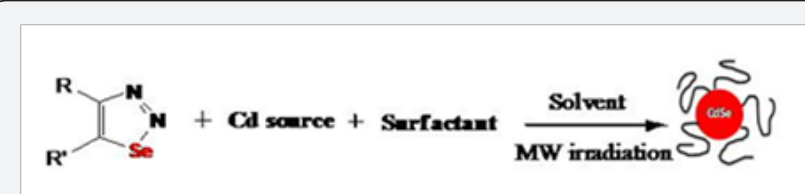

Scheme 1: Synthesis of CdSe MSNCs from 1,2,3-selenadiazoles.

This elongation can also be observed and identified by X-ray diffraction measurement where a typical CdSe QDs shows hexagonal crystal structure with all relevant Bragg's reflection but in case of MSNCs one or more peak intensity get suppressed. The synthesis of magic clusters of CdSe has been reported recently by us by employing microwave method and the finding suggested that instant while light emission is possible due to multiple trap state formation. The synthesis of MSNCs under reflux condition in $\mathrm{N} 2$ atmosphere using a solvent and oleic acid employing 1,2,3-selenadiazoles has been exploited by our research group in much details and scope of selenadazoles has been widened in nanotechnology (Scheme 1). The take home message therefore is to continue rigorous research in this area to evolve efficient and modern materials for 21st century electronics $[11,12]$.

\section{References}

1. Behrens S, Bettenhausen M, Deveson AC, Eichhofer A, Fenske D, et al. (1996) Angew Chem Int Ed Engl 35(19): 2163-2267.

2. Ptatschek V, Schmidt T, Lerch M, Muller G, Spanhel L, et al. (1998) Phys Chem 102: 85-95.

3. Soloviev VN, Eichhofer A, Fenske D, Banin U (2000) Molecular Limit of a Bulk Semiconductor: Size Dependence of the "Band Gap" in CdSe Cluster Molecules. Journal of the American chemical society 122(11): 2673-2674.

4. Peng AZ, Peng X (2002) Nearly monodisperse and shape-controlled CdSe nanocrystals via alternative routes: nucleation and growth. J Am Chem Soc 124(13): 3343-3353.

5. Rosenthal SJ, McBride J, Pennycook SJ, Feldman LC (2007) Synthesis, surface studies, composition and structural characterization of CdSe, core/shell and biologically active nanocrystals. Surf Sci Rep 62: 111157.

6. Beri RK, Khanna PK, Singh VN, Mehta BR (2011) Yellow Emitting Magicsize Cadmium Selenide Nanocrystals via a Simplified Spray Pyrolysis Method Current Applied Physics. Agris 11(3): 809-811.

7. Beri RK, Khanna PK (2010) Controlled and green synthesis of single family magic-sized CdSe nanocrystals. Cryst Engg Commn, Royal Society of Chemistry, UK.

8. Ouyang J, Zaman B, Yan FJ, Johnston D, Li G, et al. (2008) Multiple Families of Magic-Sized CdSe Nanocrystals with Strong Bandgap Photoluminescence via Noninjection One-Pot Syntheses. The Journal of Physical Chemistry C 112(36): 13805-13811.

9. Dai Q Li D, Chang J, Song Y, Kan S, et al. (2007) Facile synthesis of magicsized CdSe and CdTe nanocrystals with tunable existence periods. Nanotechnology 18(40): 405603.

10. Wu S, Liu H, Liu H, Wu Z, Du Z, et al. (2007) Synthesis and bandgap variation of molecular-size CdSe clusters via electroporation of vesicles. Nanotechnology 18: 485607.

11. Jadhav AA, Khanna PK (2015) RSC Adv 5: 44756.

12. Jadhav AA, More PV, Khanna PK (2015) RSC Adv 5: 76733.

\section{Your next submission with Juniper Publishers} will reach you the below assets

- Quality Editorial service

- Swift Peer Review

- Reprints availability

- E-prints Service

- Manuscript Podcast for convenient understanding

- Global attainment for your research

- Manuscript accessibility in different formats

( Pdf, E-pub, Full Text, Audio)

- Unceasing customer service

Track the below URL for one-step submission https://juniperpublishers.com/online-submission.php 